AC 2009-1045: TEACHING SUPPLY-CHAIN AND INVENTORY CONCEPTS THROUGH SIMULATION

Kenneth Stier, Illinois State University 


\section{Teaching Supply Chain Inventory Concepts through Simulation}

\section{Abstract}

This paper describes how effective supply chain strategies using inventory control can help companies become more competitive in the global marketplace. It describes a manual simulation activity that is used in the author's supply chain class to expose students to this concept. Instructional materials used for this simulation activity are shown.

Introduction

There are four major drivers that play a key role in the performance of any supply chain: facilities, inventory, transportation, and information ${ }^{1}$. Companies can improve their responsiveness and efficiency through these four drivers. The approach a company takes with these four drivers can determine whether or not a strategic fit is achieved across the supply chain. In other words it means that the company's competitive strategy and supply chain strategy match. The focus of this paper will be on inventory, which is one of the four drivers, and how it can have a major impact on the profitability of a company.

The accepted practice of accumulating extensive inventories can be traced back to the industrial revolution. Even as recently as in the 1990s the timeframe to deliver merchandise to the customer from inventory in a warehouse could be as long as 15 to 30 days $^{2}$. This timeframe and approach to delivering product to the customer drove the need to stockpile inventory. Today the rules of business have changed and that type of inventory strategy is no longer acceptable. Companies face intense global competition with new products being launched at a much faster pace. This has driven companies to outsource to places like China, India and countries in Eastern Europe. These changes have brought what some term a "new era" or "supply chain revolution" as companies try to reduce inventory and improve their quality. One only has to look at the fact that purchasing costs as a percent of sales for all industry in 2006 was 52\% to understand that inventory is a huge expense to companies ${ }^{3}$. It stands to reason that supply chain management has become an area that companies are giving much more attention and are integrating into every facet of their business. As companies went global with their sourcing programs over the years, procurement became a strategic function within successful organizations ${ }^{4}$. It has become important for students in engineering and technology programs to become familiar with the concepts of supply chain management, forecasting, inventory control and continuous improvement.

This paper will describe how effective supply chain strategies using inventory control can help companies become more competitive in the global marketplace. The author will explain a manual simulation that is used in his supply chain class that provides an experiential learning activity to expose students to inventory control concepts. The simulation activity is woven in with the unit on inventory in a supply chain class. 
Managing inventory and coordination of the supply chain

Inventory consists of those items that are used to support three different areas that are important to manufacturing-type companies: production, supporting activities and customer service 5 . To produce a product, raw materials are needed. Additionally, while the product is being produced there are work-in-process items that accumulate along the production line and in other locations. While production is taking place, maintenance and repair activities have to be done to keep the operations flowing smoothly. These supporting activities require inventory in the form of supplies. Once the product is sold to the customer it is important for the company to service it. Finished goods and spare parts are usually required for this function. How well a company manages its inventory in these three areas can have a dramatic effect on the supply chain's efficiency and responsiveness ${ }^{6}$. Excess inventory will normally drag down the financial performance of a company. At the same time, there needs to be enough inventories available in the supply chain to support production and have a variety of products to generate sales. Supply chain managers in companies today often find themselves struggling to make the best decisions with regard to this balancing act. Inventory decisions can be high risk and will have a big impact on the financial performance of a company ${ }^{7,8}$. The objective of inventory management and control should be to help the company realize a profit while satisfying the customer by meeting the schedule for deliveries. Companies like Deere \& Company and IBM have tackled this problem over recent years and serve as models for others ${ }^{9,10}$.

Carrying costs are one of the key concerns in determining the cost of inventory to a company. Carrying costs are determined by taking the average times the inventory-carrying rate $^{11}$. Determining these costs has become a much more precise process and consequently this data has become very important in decision-making for inventory management and control. One of the biggest challenges a company may face with determining the cost of their inventory is to determine the carrying rate. Factors that are often included in determining the carrying rate consist of such things as the interest rate on money, loss due to obsolescence, amount of scrap, space needed for storage, taxes, insurance, labor, handling, storage costs, equipment needed, lost opportunity, depreciation, etc. These costs can vary widely from one company to another and there are no reliable standards for calculating carrying costs. Each company normally has to review all their cost factors and determine which ones are relevant for them ${ }^{12}$.

When tracking inventory it can be divided up into different categories. One category or type of inventory is cycle stock. This consists of components or products that are received in bulk by a downstream partner. The components are gradually used up and then replenished again in bulk by an upstream partner. Companies need to guard against any uncertainty that may exist in the supply chain if there should happen to be any interruptions in the flow of inventory from their suppliers. As a result, they hold extra inventory which is known as safety stock. This category of inventory will fluctuate in amount based on the degree of uncertainty that exists within a supply chain. Holding more safety stock will result in higher costs to the company ${ }^{13}$.

Companies will normally use one of two types of review systems to replenish the cycle stock. The periodic review system is one type. With this system companies check their inventory level of an item at regular intervals and re-stock to some pre-determined level. The 
reorder point is often driven by the intervals that exist between each review. This type of inventory review system is not well suited for managing critical and/or expensive inventory items. The perpetual review system is the second method to control inventory levels. With this system inventory levels are monitored constantly to determine when to replenish inventory. The re-order point is driven by such factors as the acceptable level of safety stock, demand for the inventory and supply chain considerations ${ }^{14}$.

Coordination in the supply chain can also have a big impact on the financial performance of the system. Effective supply chain coordination can improve the overall financial performance of the system if all stages of the supply chain take action together. This requires that different areas within the supply chain must consider the impact that their decisions will have on other areas ${ }^{15}$.

Companies such as Proctor \& Gamble and Hewlett-Packard have experience the bullwhip effect as a result of the lack of coordination in the supply chain ${ }^{16}$. The bull whip effect is a fluctuation in orders that is experienced by members in a supply chain such as retailers, wholesalers, manufacturers and suppliers. This often occurs when each stage of the supply chain focuses solely on their local objective. As a result, that stage of the supply chain may be optimized at the expense of the entire system. Total supply chain profits often are improved when good coordination exists within the system. Lack of coordination in a supply chain system can increase variability and uncertainty. Consequently, this will increase costs for such things as manufacturing, inventory, transportation and labor for shipping and receiving. In addition, replenishment lead times may be increased and the product availability to the customer could fluctuate to the point that more back orders and stock outs will occur. This can negatively affect the performance of the different constituents in the supply chain and the relationships between them. Situations like this can become an even bigger issue when one group of constituents assigns blame to the other. Trust among the supply chain partners can be compromised and will make future coordination efforts even more difficult ${ }^{17}$.

Simulating the performance of a simple supply chain

The author has used a manual simulation called the "The Beer Game" to simulate the performance of a simple supply chain and allow the students to experience the importance of coordination within a supply chain, as well as the bull whip effect. The game originated at the Massachusetts Institute of Technology and has been used in other educational settings over the years. The key constituents in the supply chain for this game are a manufacturer, a distributor, a wholesaler, and a retailer.

The author introduces the students to the manual simulation during the unit on inventory. Background information on inventory control is presented first and then the author explains the simulation to the students as a means to reinforce concepts that are included in the unit. The class is divided up into groups of five. Each group is given a set of laminated drawings. The drawings consist of a layout for each stage of the supply chain. There is a drawing for the retailer, wholesaler, distributor and manufacturer. With a class of 25 there would be five groups and each group would have the same set up with the laminated drawings. 
The students are told that they will be playing a game where their inventory will be beer. They are also told that poker chips will be used to simulate cases of beer. The author then goes through a series of leading questions with the students to issue the laminated stages/stations of the supply chain to them. First the author asks the students where they would go to purchase beer. Eventually they respond with the "retailer" and one student in each group is asked to come up and pick up the laminated layout for the retailer stage in the supply chain. Figure one shows a two dimensional computer-aided design drawing of the retailer station drawn in AutoCAD software. The drawing was plotted on an ANSI D- 22 x 34 in. (landscape layout) size paper and then laminated. There is one laminated retailer layout for each of the groups that play the beer game in class. One player in each group is assigned to the retailer stage to role play this supply chain partner. The end customer is the retailer's customer and is the source for the orders of beer at the retailer station. Once the retailer fills the end customer's order, s/he sends another order to the wholesaler.

\section{RETAIIER LAYOUT}

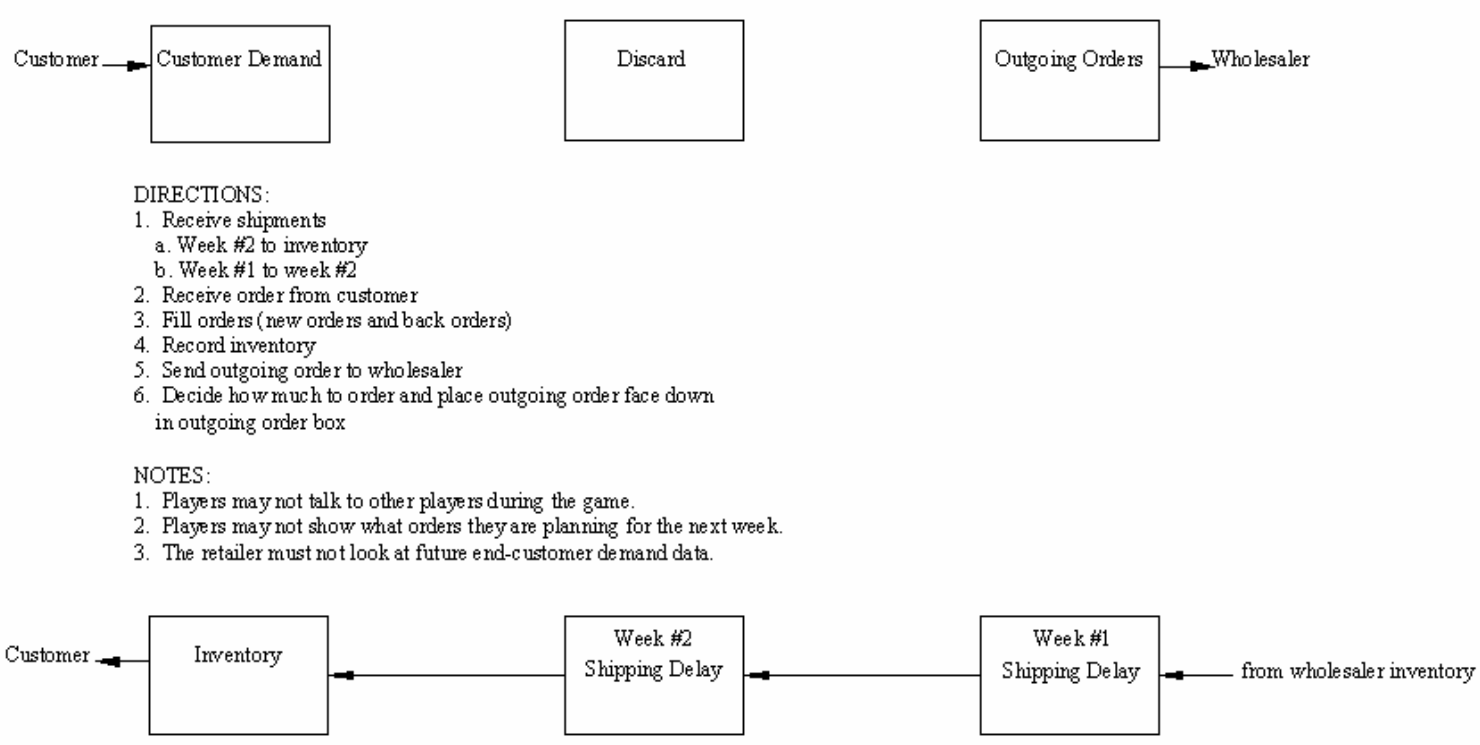

Figure 1. Drawing of the retailer station.

The wholesaler is the retailer's supplier and therefore is the next partner in the supply chain layout of the beer game. To lead into distributing the wholesaler laminated layout, the author asks the students where the retailer purchases beer. Once the wholesaler has been identified as the answer a student from each group is asked to pick up the laminated layout for that stage of the supply chain. Figure two shows a two dimensional computer-aided design drawing of the wholesaler station. The drawing was plotted on the same size paper as the retailer station and then laminated. Again, there is one laminated wholesaler layout for each of 
the groups that play the beer game in class and one player in each group is assigned to the wholesaler station to role play this supply chain partner. The wholesaler's customer is the retailer during the game and the distributor is the supplier to the wholesaler station.

WHOLESALER LAYOUT

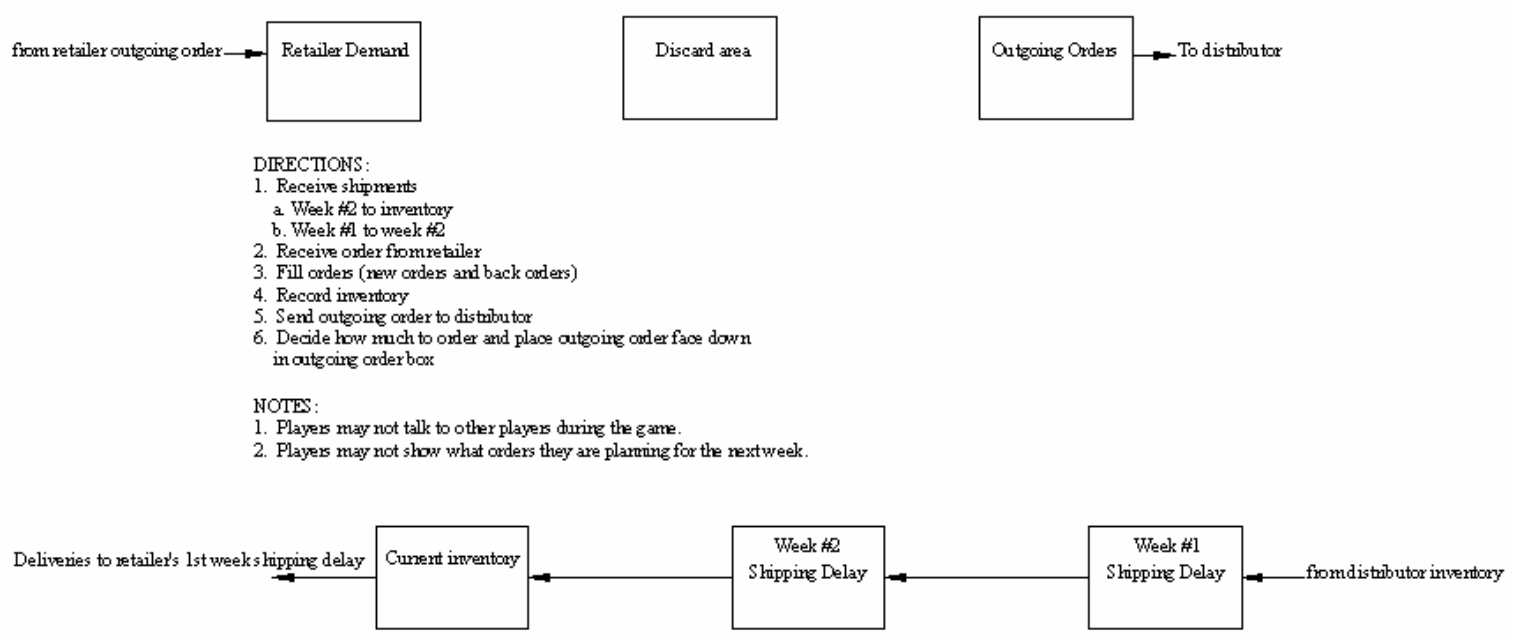

Figure 2. Drawing of the wholesaler station.

Next the author asks the students where the wholesaler purchases beer and eventually they realize it is the distributor. A student from each group is then asked to pick up a laminated layout for the distributor. Figure three shows the laminated layout of the distributor station. There is one laminated distributor layout for each of the groups and one player in each group role plays this supply chain partner. As can be seen in figure three, the distributor's customer is the wholesaler during the game and the manufacturer is the supplier to the distributor station. 


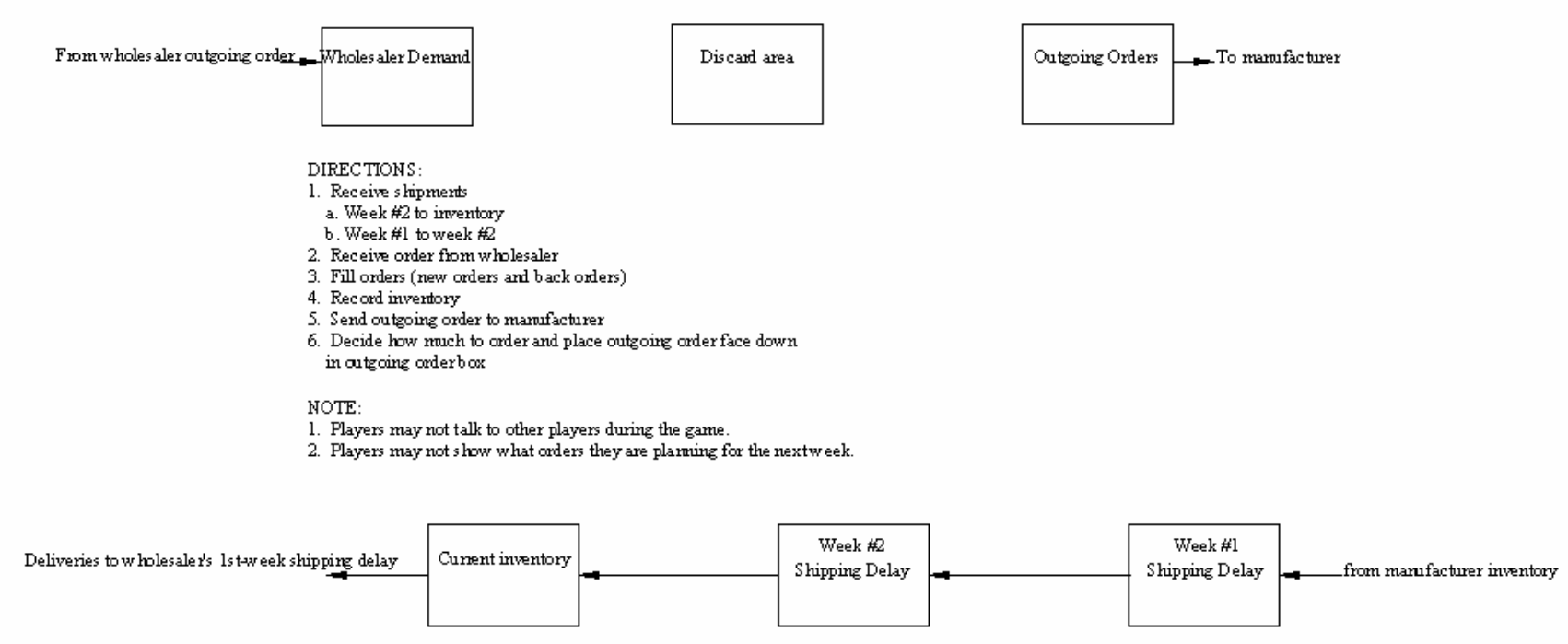

Figure 3. Drawing of the distributor station.

The wholesaler sends orders to the manufacturer during the game so the manufacturing station is the next stage in the supply chain. The students are asked where the distributor purchases beer and they are given the laminated layout for the manufacturer when they identify that supply chain partner. Figure four shows the laminated layout of the manufacturing station.

Once the students have their laminated layouts and identified who will role play the different constituents in the supply chain a fifth person is assigned to each group and is asked to transport poker chips to locations where they are needed. The author then calls the class around one supply chain system with all the stages and explains the layout of each work station in the supply chain, the purpose of the materials at each station and the directions on the laminated layouts. The author talks the students through the playing procedures of each stage of the beer game and then has the students do a test run for two rounds to further experience the game before playing it. 


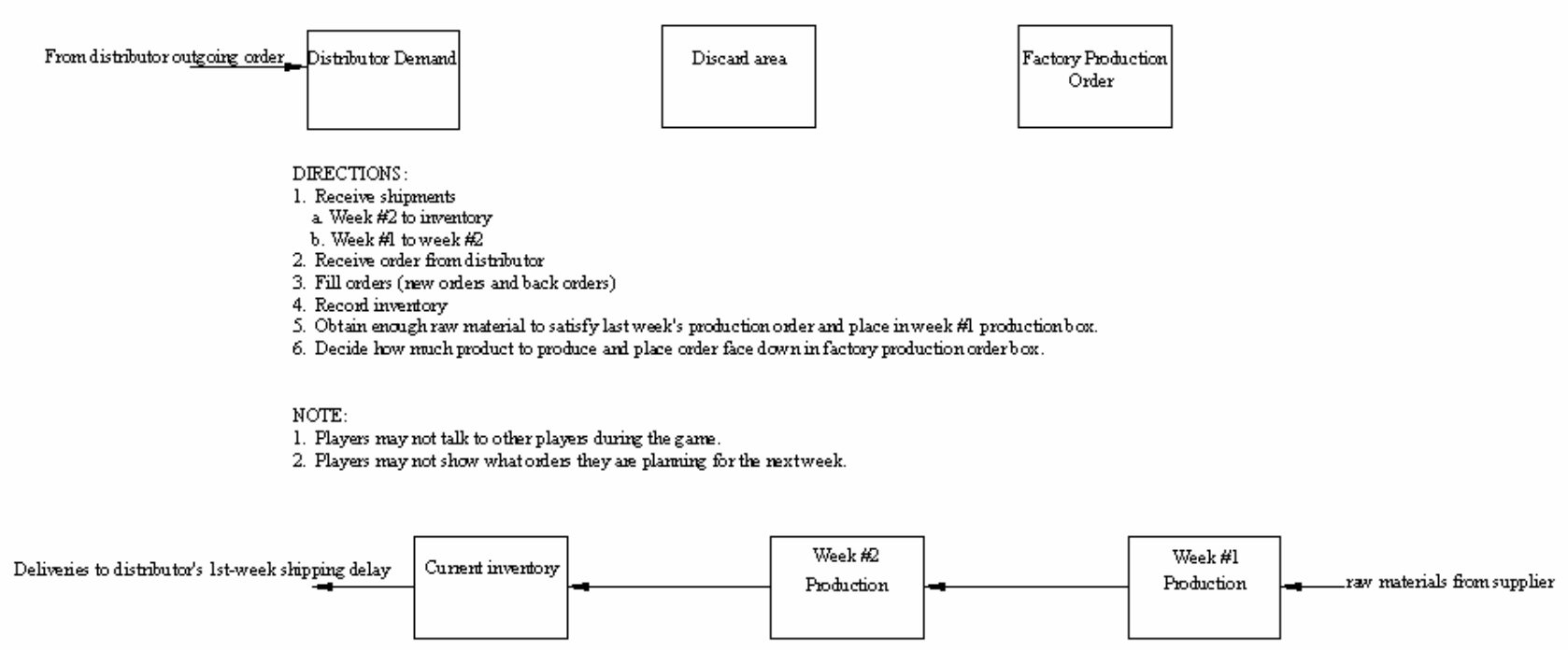

Figure 4. Drawing of the manufacturer station.

Each supply chain participant follows the same set of activities:

1. The participant forecasts customer demand for the upcoming weeks and then orders beer from her/his supplier (or schedules beer production if $s /$ he is the manufacturer), which then takes several weeks to materialize.

2. The participant manages inventories as best s/he can to minimize back-order and inventory carrying costs.

3. The participant fills her/his customer orders each week and creates back orders if demand cannot be met.

There is no transportation delay from the retailer to the end customer. For the other supply chain members, there is a two-week transportation delay from customer's order to the shipment receipt. It also takes two weeks to complete a production lot at the factory, which would then be ready to fill customer orders.

Each game consists of four game boards with one player at each board and a transportation person. There are four to five beer games going at once, depending upon the number of students in the class (20-25). Each player at a board has an inventory record sheet on their table which allows them to keep an inventory record for their specific game board. 
How the manual simulation works

The game progresses as follows to simulate inventory flowing through a supply chain and how the bull whip effect can occur:

Starting conditions. To start the game, the system is preloaded. It is assumed that each member (except the manufacturer) has twelve cases of beer in current inventory, four cases in the second week's delay of incoming shipments, and four cases in the first week's delay of incoming shipments (see the bottom of figures 1-3). The manufacturer has twelve cases of beer in current or ending inventory, four cases of beer in the second week's production delay, and four cases in the first week's production delay (see the bottom of figure 4). Each player also has an outgoing order of four cases sitting in their outgoing order box (or production order box) as shown in the upper right corner of figures one to four. The retailer must start with twenty weeks of endcustomer demand (or longer), provided by the game coordinator or instructor.

Procedures.

1. Each member ships his beer. S/he moves the cases of beer from the second week's delay to current (or beginning) inventory and from the first weeks delay to the second week's delay. For the manufacturer, move beer from the second week's production delay to current (or beginning) inventory and from the first week's production delay to the second week's production delay (see figures 1-4).

2. Each member receives their customer orders. The retailer reads their customer demand and then places the card face down in the discard area. The retailer then fills the order (plus any back orders) by moving beer cases from current (or beginning) inventory to the customer delivery container (an area off the board). The retailer then records the ending inventory amount and any current back orders in the columns provided on the Inventory Record Sheet. Next, the retailer sends last week's outgoing order to the wholesaler's incoming order box. Finally, the retailer decides how much to order by writing an order on the order sheet provided and placing it face down in the outgoing order box.

When the wholesaler receives the retailer's order, the supply chain partner follows the same steps as above. The wholesaler fills the order and any back orders from current (or beginning) inventory (note that this increases the number of cases in the retailer's first week's shipping delay). S/he records the ending inventory and back orders and then sends last week's outgoing order to the distributor. Then the wholesaler decides how much to order and places the order sheet face down in the outgoing order box.

The distributor goes through the same steps when s/he gets the order from the wholesaler. The manufacturer follows the same steps also, except instead of sending last week's outgoing order somewhere, s/he reads the outgoing order and fills the production request by transferring that number of cases from its raw materials storage area to the first week's production delay (this simply creates the cases needed for the order). Steps 1 and 2 are then repeated until the game limit of twenty rounds of orders is reached. 
While playing the beer game players must take care not to talk to the other participants during the game or to show what orders they are planning for the next week. The retailer must not peek at future end-customer demand data, provided by the instructor. At the end of the twenty weeks (or shorter if time does not permit) players determine the total cost of their inventories and back orders on the inventory record sheet. Figure 5 shows the inventory record sheet the author uses.

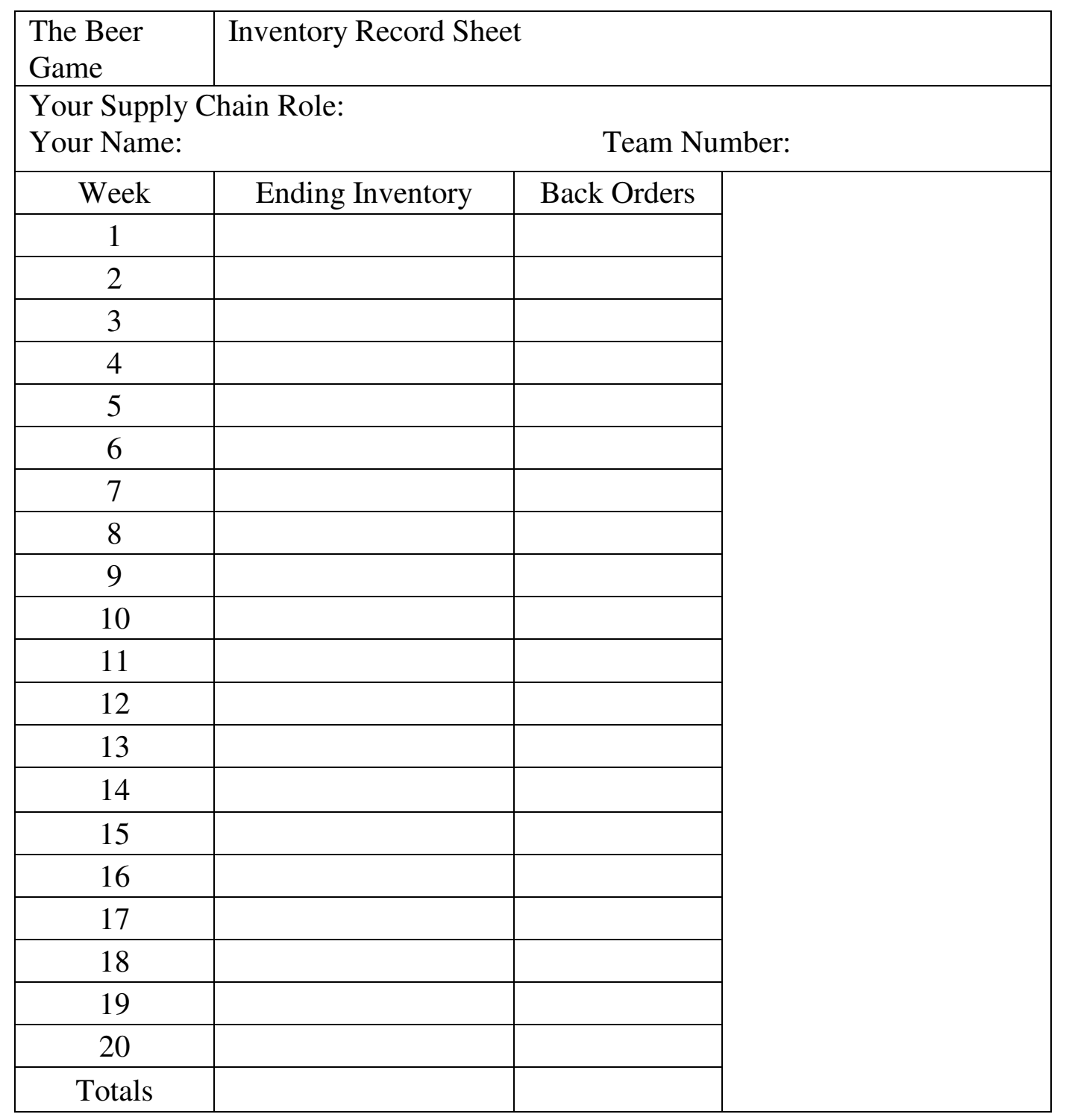

Figure 5. The inventory record sheet used in the simulation

Back orders cost $\$ 2.00$ per unit per week, and inventories cost $\$ 1.00$ per unit week. Given these costs, the basic strategy should be to attempt to minimize total inventory and back-order costs, while forecasting the next period's demand accurately. The winning team is the team with the lowest total supply chain costs (inventory + back order). 
To help the students synthesize what they have learned as a result of playing the beer game and to stimulate discussion, the author passes out the questions shown in figure six. Each student is asked to answer the questions and submit their answers for evaluation. The author returns the graded answers to the students at the next class period and uses this as a means to foster discussion.

Name: Total Points:

\section{TEC370 Supply Chain Logistics}

Directions: Please complete the following questions after completing the game and submit it to your instructor.

\section{The Beer Game Questions (8 pts.)}

1. All players but the retailer should answer this question. The retailers answer question 5 instead. What do you think the retailer's customer demand pattern looked like? How did your customer's orders vary throughout the game? (2pts.)

2. What happens to the current inventory levels as we move backward, up the supply chain from the retailer to manufacturer? Why? (2 pts.)

3. How could the supply chain members reduce total inventory and back-order costs in the future? ( 2 pts.)

4. List at least two important concepts the game is illustrating. (2 pts.)

5. This question is for the students who were the retailers.

The typical measures of inventory exposure are time duration, depth and width of commitment. Explain how a retailer's inventory risk can be viewed with regard to these three measures. (2 pts.)

Figure 6. The questions posed to the students at the end of the simulation.

Summary and lessons learned

This paper overviews the beer game which is a manual simulation that shows students the importance of controlling inventory levels, the bull whip effect and, the importance of coordination and communication within the supply chain. Laminated work stations with directions and a layout for the materials used to play the game are given to the students by the instructor. The workstations are set up in a straight line to simulate the flow of materials through 
a supply chain. The students experience firsthand how difficult it is to determine the appropriate quantities of inventory to order when there is no communication or coordination in the supply chain system. The economics of this whole situation is driven home to the students by having them record their inventory and back orders for each week. Costs are then applied to quantities to determine how well their supply chain performed financially.

Students quickly learn the importance of communication to achieve supply chain coordination. By not allowing them to look at the orders coming into their station prior to placing their orders to their supplier, it becomes a guessing game for them to determine the quantities they will need for each week. Each station focuses on trying to optimize their inventory and typically does not do well because of the lack of communication and coordination in the supply chain layout. This further reinforces the importance of coordination throughout the entire supply chain to maximize total supply chain profits. Even if one station does manage to break even or become profitable, the system as a whole does not. The phenomenon of uncertainty and fluctuation in the system is experienced by the students. They learn firsthand what the bullwhip effect really is like.

The author has found that this is an activity that students typically get excited about and enjoy because the inventory used in the game is something most of them can relate to real well. When starting the game the students' biggest challenge is mastering the rules of the game. That is why the author has found doing a test run with each group of students really helps them grasp the rules of the game. Anecdotal feedback from the students has indicated that they typically enjoy this activity and learned a lot about supply chain concepts as a result of participating in it. Overall, the author has found that the beer game is an excellent way to introduce the supply chain concepts being taught and foster discussion among the students in an enjoyable manner.

\section{Bibliography}

${ }^{1}$ Chopra, S. \& Meindl, P. (2004). Supply chain management: Strategy, planning, and operations. $2^{\text {nd }}$ ed. Upper Saddle River, NJ: Pearson Prentice Hall.

${ }^{2}$ Bowersox, D. J., Closs, D. J. \& Cooper, M. B. (2007). Supply chain logistics management, $2^{\text {nd }}$ ed. New York, NY: McGraw-Hill Irwin.

${ }^{3}$ Heizer, J. \& Render, B. (2007). Operations management, $8^{\text {th }}$ ed. Upper Saddle River, NJ: Pearson Prentice Hall. 10(9), 22.

${ }^{4}$ Loftus, P. D. (2006, December). Procurement for high performance. Supply Chain Management Review,

${ }^{5}$ Bozarth, C. C. \& Handfield, R. B. (2006). Introduction and supply chain management. Upper Saddle River, NJ: Pearson Prentice Hall.

${ }^{6}$ Chopra, S. \& Meindl, P. (2004). Supply chain management: Strategy, planning, and operations. $2^{\text {nd }}$ ed. Upper Saddle River, NJ: Pearson Prentice Hall.

${ }^{7}$ Peele III, H. E., Trushinski, T. \& Stobo, A. (2008, Quarter 2). Now you see it! Council of Supply Chain Management Professionals Supply Chain Quarterly, 2(2), 54-62.

${ }^{8}$ Quittner, J. (2007, August/September). The China code. BusinessWeek SmallBiz, 40-46.

${ }^{9}$ Cooke, J. A. (2007, April). Running inventory like a Deere. Council of Supply Chain Management Professionals Supply Chain Quarterly, 1(2), 47.

${ }^{10}$ Drickhamer, D. (2004, May). Supply-Chain superstars, IndustryWeek, 253(5), 59-64. 
${ }^{11}$ Harding, M. L. (2006, October). What's the cost of your inventory? WERC Sheet, 29(9), 6-7.

${ }^{12}$ Harding, M. L. (2006, October). What's the cost of your inventory? WERC Sheet, 29(9), 6-7.

${ }^{13}$ Bozarth, C. C. \& Handfield, R. B. (2006). Introduction and supply chain management. Upper Saddle River, NJ: Pearson Prentice Hall.

${ }^{14}$ Bowersox, D. J., Closs, D. J. \& Cooper, M. B. (2007). Supply chain logistics management, $2^{\text {nd }}$ ed. New York, NY: McGraw-Hill Irwin.

${ }^{15}$ Chopra, S. \& Meindl, P. (2004). Supply chain management: Strategy, planning, and operations. $2^{\text {nd }}$ ed. Upper Saddle River, NJ: Pearson Prentice Hall.

${ }^{16}$ Chopra, S. \& Meindl, P. (2004). Supply chain management: Strategy, planning, and operations. $2^{\text {nd }}$ ed. Upper Saddle River, NJ: Pearson Prentice Hall.

${ }^{17}$ Chopra, S. \& Meindl, P. (2004). Supply chain management: Strategy, planning, and operations. $2^{\text {nd }}$ ed. Upper Saddle River, NJ: Pearson Prentice Hall. 